\title{
Multiple Intelligence Theory Can Help Promote Inclusive Education for Children with Intellectual Disabilities and Developmental Disorders: Historical Reviews of Intelligence Theory, Measurement Methods, and Suggestions for Inclusive Education
}

\author{
Junichi Takahashi \\ Department of Developmental Disorders, National Institute of Mental Health, National Center of Neurology and \\ Psychiatry, Tokyo, Japan \\ Email: j_taka@ncnp.go.jp
}

Received July $5^{\text {th }}$, 2013; revised August $5^{\text {th }}$, 2013; accepted August $12^{\text {th }}, 2013$

Copyright (C 2013 Junichi Takahashi. This is an open access article distributed under the Creative Commons Attribution License, which permits unrestricted use, distribution, and reproduction in any medium, provided the original work is properly cited.

\begin{abstract}
Inclusive education, based on the principle that all children (including those with disabilities) should receive similar education, has been recently adopted in primary and secondary schools throughout several countries. Within an inclusive education context, teachers are faced with the challenge of developing their knowledge and skills necessary to properly assess the intellectual abilities of a wide range of children. Although intelligence has been examined for over 100 years, researchers are still debating what abilities should or should not be classified as belonging to the domain of intelligence. In order to effectively apply intelligence theory and assessment methods for inclusive education, we compared traditional intelligence theory (Spearman's two-factor model) with a more recent intelligence theory (Gardner's multiple intelligence theory). Spearman's theory focuses on elementary perceptual processes by using the single $g$ factor, whereas Gardner's theory recognizes several types of intelligence. On the basis of these reviews, we propose the utility of multiple intelligence theory for inclusive education, considering the various profiles of intelligence shown by children with intellectual disabilities and developmental disorders.
\end{abstract}

Keywords: Multiple Intelligence Theory; Inclusive Education; Intellectual Disabilities; Developmental Disorders

\section{Introduction}

In Japan, the educational system of compulsory schools for children who need special education began in 1979. All children who had various forms of disability could receive school education. Attending special support school means that these children receive compulsory education. Thus, the number of children who attended special support schools continued to increase. According to a report by MEXT (Ministry of Education, Culture, Sports, Science, and Technology) in 2008, 0.6\% (60,302 children) of all children (primary and secondary schools) attended a special support school, and 1.2\% (124,166 children) of all children attended a special support class within a general school.

In order to support children's education, special education teachers need to assess whether or not special education is needed for certain children. Thus, it is necessary to precisely measure children's intellectual abilities (Koegel, Matos-Freden, Lang, \& Koegel, 2012; Pivik, McComas, \& Laflamme, 2002). Special education teachers need to acquire the knowledge and skills required for proper measurement of children's intelligence (i.e., IQ: intelligence quotient) in order to adapt their teaching to children with disabilities (i.e., intellectual disabilities, autism spectrum disorder, attention deficit hyperactivity disorder, dyslexia, and learning disabilities).

Recently, inclusive education is being seen more broadly as a reform of the educational system around the world (UNESCO, 2001). Children who need special education, in addition to typically developing children, should be educated together in a general classroom. Further, in Japan, part of the School Education Act was revised in 2007 with the intention that the educational system supports each child's special needs. Here, education for children with disabilities extends to general society in addition to special support schools. Efforts of teachers, along with the government, school boards, and principals, are needed to facilitate inclusive education. In this situation, teachers have to assess children's intelligence in order to adapt their teaching to all children, including children with disabilities (Pivik et al., 2002). General education teachers need to conduct measurements of children's behavior and develop intervention plans based on each child's symptoms (Koegel et al., 2012). However, general education teachers might have difficulty working with children with disabilities given their lack of experience in dealing with this student population (Koegel et al., 2012; Robertson, 
Chamberlain, \& Kasari, 2003; Takahashi, in Press).

However, researchers are still debating what sorts of abilities should and should not be classified as part of intelligence (e.g., Gottfredson, 2004). In this paper, first, we review traditional intelligence theory and assessment methods and discuss their theoretical problems with regard to teaching methods for children with disabilities. Second, we review more recent intelligence theory, such as multiple intelligence theory and its assessment methods. On the basis of these reviews, we suggest that multiple intelligence theory could be applied to inclusive education by focusing on disabled children's uneven intellectual profiles.

\section{Traditional Intelligence Theories and Assessments}

Intelligence has been studied for about 100 years, in which researchers have examined intelligence assessment methods and its theory. Considering the assessment methods of intelligence, two types of intelligence measures were proposed: one aimed to assess elementary perceptual processes (e.g., Cattell, 1890; Galton, 1883; Spearman, 1904), and the other focused on an assessment of complex cognitive processes (e.g., BinetSimon, 1905; Wechsler, 1997). The validity of these findings has yet to be fully discussed according to previous studies from Spearman (1904) and Binet and Simon (1905).

Intellectual assessment methods were first derived from Galton's measurement of elementary perceptual processes. Galton measured auditory and visual sensory discrimination abilities, reaction times to stimuli, and hand squeeze pressure performance on a dynamometer. Galton believed that sensations were the foundation for complex cognitive functions. He assumed that people with high in intelligence could effectively discriminate stimuli compared to people with low in intelligence (Galton, 1883). Cattell (1890) expanded Galton's intelligence assessments and proposed ten psychological components, such as tactile discrimination, thresholds for pain, weight discrimination, and reaction times to auditory stimuli.

In contrast to these scales, Binet focused on complex mental processes. In 1905, Binet and Simon published the "measuring scale of intelligence” to assess children who needed special education in Paris (Binet \& Simon, 1905). This measurement includes 30 subtests, such as naming, semantic judgments, memory, reasoning, and digit span. In each subtest, examination items were arranged on the basis of difficulty. In 1908, they revised the scale by grouping tests by age level (e.g., for the digit span subtest, longer spans were intended for older children). In the revised version of Binet-Simon's scale, assessment began at the child's age level and proceeded to a higher or lower level based on performance criteria. According to this method, mental age (the highest age level) was defined. The Binet-Simon scales have influenced later intellectual assessment methods (Boake, 2002). In the 1930's, Wechsler focused on a wide range of intellectual abilities and a broadband intelligence test for adults because he considered intelligence to be guided by several personality aspects. In contrast to the early emphasis on the assessment of elementary perceptual abilities (e.g., Spearman, 1904), Wechsler suggested that intelligence should be assessed in relation to a person's overall ability, similar to Binet. The Wechsler intelligence scales are classified as the WAIS (Wechsler Adult Intelligence Scale: Wechs- ler, 1997), WISC (Wechsler Intelligence Scale for Children: Wechsler, 1991), and WPPSI (Wechsler Preschool and Primary Scale of Intelligence: Wechsler, 1999) for adults, school-aged children, and preschoolers, respectively. These scales can measure specific aspects of ability through various subtests; these subtests yield both a verbal and performance IQ (VIQ and PIQ, respectively), in addition to a full scale IQ (FSIQ). For example, the WAIS-III (Wechsler, 1997) is composed of seven subtests of verbal abilities (Vocabulary, Similarities, Information, Comprehension, Arithmetic, Digit Span, and Letter-Number Sequencing) and seven subtests of performance abilities (Picture Arrangement, Picture Completion, Block Design, Matrix Reasoning, Digit-symbol Coding, Symbol Search, and Object Assembly). The Wechsler intelligence scales have been recommended as a crosscheck for neuropsychological functions among children with disabilities (e.g., Kaufman, Long, \& O’Neal, 1986).

In contrast to the aforementioned intelligence tests, the study of intellectual testing theory has not advanced much. Theoretical considerations have been discussed by Spearman (1904). He obtained a significant positive correlation between sensorydiscrimination ability and children's academic performance. For instance, children with a large capacity for sensory-discrimination tend to show higher academic performance. Thus, he concluded that sensory-discrimination ability shares a similar capacity with academic performance among children. On the basis of these accounts, Spearman developed an intelligence theory based on the assumption that sensory-discrimination capacity might coincide with intelligence, which was labeled as a single $g$ factor for general intelligence. He also proposed the specific source of variance (s); these proportions have been referred to as the "two-factor model" of intelligence (Figure 1(a)).

\section{Problems of Traditional Intelligence Theory in Consideration of Children with Developmental Disorders}

Traditional intelligence theory lacked innovation in terms of developmental and cognitive approaches to intelligence (e.g., Sternberg \& Kaufman, 1996). In addition, traditional intelligence theory did not have much ecological validity (Almeida, Prieto, Ferreira, Bermejo, Ferrando, \& Ferrandiz, 2010). As Almeida et al. (2010) indicated, since traditional intelligence theory assessed students' maximal performance in situations related to school settings, there was little focus on the most valuable aspects of cognition within real life settings. Moreover, traditional theorists assessed students' performance in an overly abstract manner without consideration of cultural context and differences between social groups. Sternberg (1997) also argued that most conventional concepts of intelligence are too narrow and deal only with a small portion of intelligence as a whole. Sternberg (1985) proposed three basic concepts (the ability to adapt to one's environment, the ability to deal with novel tasks, and the ability to develop expertise) and suggested that intelligence depends on acquiring these information-processing skills and strategies.

For children with developmental disorders, the problems of traditional intelligence theory are more evident. The two-factor model cannot account for children with developmental disorders. Children with developmental disorders, such as high functioning autism spectrum disorder, attention deficit hyperactivity disorder, and learning disorders, generally display normal IQ 
levels (i.e., IQ more than 70). However, these children show an uneven profile among intellectual subtests (e.g., Lincoln, Courchesne, Kilman, Elmasian, \& Allen, 1988; Siegel, Minshew, \& Goldstein, 1996; Szatmari, Tuff, Finlayson, \& Bartolucci, 1990). For example, when assessing Wechsler Intelligence Scale performance, the intelligence profile of children with autism spectrum disorders is characterized by VIQ (verbal IQ) < PIQ (performance IQ) with the lowest subtest performance on the comprehension subtest and highest performance on the Block Design subtest. However, these children's FSIQ (full scale IQ) is over 70, indicating a normal IQ level. The two-factor model might not correctly assess abilities for these children given that the model relies more on the single $g$ factor and does not account for the uneven profiles in subtest performance among children with autism spectrum disorders. Similar arguments against a single $g$ factor for assessing children with developmental disorders have been proposed elsewhere (e.g., Anderson, 1998).

In addition, current assessment methods only include determinate aspects of children's abilities. For example, although the Wechsler Intelligence Scales can measure verbal or logical abilities through traditional paper-and-pencil tests, people should be measured on abilities that are more relevant to their everyday environment. Although IQ scores for children with developmental disorders are generally lower than those of typically developing children when using the Wechsler Intelligence Scale (e.g., Happe, 1994), in terms of performance on specific tasks, such as visual search or memory, performance of children with developmental disorders is as good or better than that of typically developing children (e.g., Dawson, Soulieres, Gernsbacher, \& Mottron, 2007). From perspective, traditional intelligence theory and its assessment would be associated with determinate aspects of intelligence, which would not be ecologically valid.

More recently, Gardner (1983) proposed a new approach for the conceptualization of intelligence, which he termed multiple intelligence (MI) theory (Figure 1(b)). Gardner (1998) argues for various types of intelligence (at least eight independent intelligences). Although children have the capacity to use these eight forms, most children show different profiles in how they blend intelligences to solve problems. Thus, MI theory could potentially account for an uneven Wechsler intelligence profile among children with developmental disorders. Below, we review Gardner's MI theory in more detail.

\section{Multiple Intelligence Theory}

The MI theory (Gardner, 1983, 1993, 1998) adds a nuanced view to intelligence theory. Gardner defined intelligence as the ability to solve problems or create products in one or more cultural settings. He proposed that there are at least eight independent intelligences: verbal-linguistic, logical-mathematical, spatial, bodily-kinesthetic, musical, interpersonal, intrapersonal, and naturalist (Gardner, 1998). For example, musical intelligence is the ability to produce and appreciate rhythm, pitch, and timbre, while spatial intelligence refers to the ability to mentally represent and manipulate objects, navigation, mechanics, sculpture, and geometry. Based on several domains of study (e.g., psychology, case studies, anthropology, cultural research, and biology), the eight intelligences are classified on the basis of 1) potential independence with neuropsychology; 2) the existence of a "genius" in each intelligence; 3 ) a specific applica-

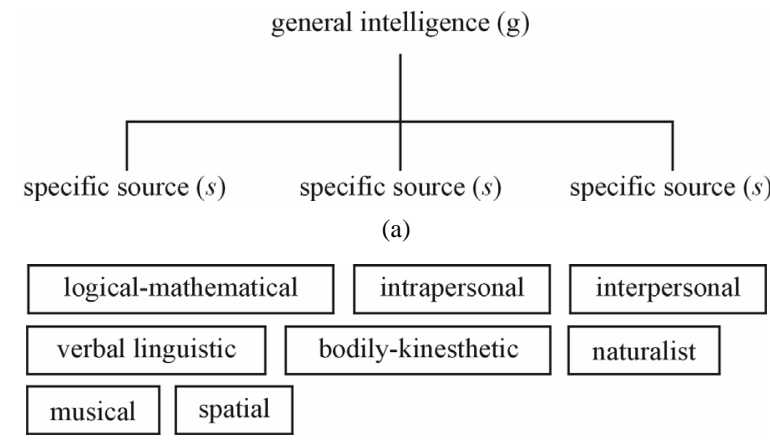

(b)

Figure 1.

The schematic diagram of two-factor model (a) and MI model (b). (a) Spearman assumed that sensory-discrimination capacity might be associated with intelligence. He labeled it as a single $g$ factor (general intelligence). He also assumed the specific source of variance (s), for example, verbal comprehension, processing speed, or perceptual organization; (b) Gardner proposed at least eight independent intelligences in MI theory.

tion; 4) differences in developmental processes between people with high and low abilities in each intelligence; 5) scientific validity related to evolution; 6) agreement with psychophysical findings; 7) agreement with psychometric findings; and 8) an encoding system. The MI theory uses the concept of modules. Modules are neural structures that process particular content. In the case of visual processing modules, color, shape, or face stimuli might be processed specifically. People have the capacity for all eight intelligences and show uneven profiles by blending some intelligence to adapt to the environment (Gardner \& Hatch, 1989). For instance, a therapist would have high verbal-linguistic ability and sensitivity to the sounds and construction of language. Surgeons would have high visual acuity and spatial intelligence in order to manipulate the scalpel and bodily-kinesthetic dexterity in order to properly use the tool. Scientists require verbal-linguistic and logical-mathematic intelligence in order to indicate and explain new findings. Moreover, scientists also should have high interpersonal intelligence to better interact with colleagues and be a part of a smoothly functioning laboratory.

Emotional intelligence (EI) theory has also been proposed as another facet of intelligence (Salovey \& Mayer, 1990). Since "emotional thoughts” (Leeper, 1948) are part of "logical thoughts," which contribute to general intelligence, there was little research on emotional intelligence for nearly forty years (Derksen, Kramer, \& Katzko, 2002). When Gardner (1983) proposed MI theory, researchers began to revisit EI theory. EI theory is defined as the capacity to process emotional information accurately and efficiently, including information relevant to the recognition, construction, and regulation of emotion within oneself and others (Salovey \& Mayer, 1990). In order to assess EI, three main tests have been developed: the Mayer-SaloveyCaruso Emotional Intelligence Test (MSCEIT: Mayer, Salovey, \& Caruso, 2002), Emotional Quotient Inventory (EQ-I: Bar-On, 1997), and Self-Report EI Test (SREIT: Schutte, Malouff, Hall, Haggerty, Cooper, Golden et al., 1998). MI theory is different from EI theory in that the former focuses on the importance of cognitive functioning rather than emotional functioning within the domain of intelligence.

Although Gardner provides theoretical consideration for MI theory, he details few assessment methods for measuring these 
facets of intelligence. Almeida et al. (2010) examined how traditional intelligence tests and those based on MI theory are interrelated. They used the Battery of Differential and General Aptitudes (BADyG: Yuste, Martinez Arias, \& Galve, 1998) as an assessment method. The BADyG is composed the BADyG-I (designed for respondents aged four to six years) and the BADyG-E1 (six to eight years). The BADyG-I is composed of six subtests: numerical quantitative concepts, information, figural vocabulary, non-verbal mental ability, reasoning with figures, and puzzles. The BADyG-E1 is composed of eight subtests: logical reasoning, analogical relationships, numerical problems, logical matrices, numerical calculus, complex verbal orders, rotated figures, and discrimination of differences. Almeida and colleagues used activities to evaluate MI proposed by Gardner, Feldman, and Krechevsky (1998) measured on a Likert scale. Verbal-linguistic intelligence was assessed with a "story-telling" task in which children play with a model that has scenery and several characters. Children are then asked to make up a story and tell it to the administrator. In addition, this facet of intelligence was assessed with a "reporter" task in which children were asked to tell what happened in a video after being shown a short, voiceless video. Logical-mathematical intelligence was assessed with the "game of the dinosaur" task, which was a table game. Children advanced positions depending on a score acquired with two dice: one marks the number of positions, and the other marks the direction to follow with a backward movement and advanced sign. Children were asked which die throw would be needed to win the game. This task measured numerical reasoning, logical reasoning, and spatial reasoning. Spatial intelligence was assessed with the "create a sculpture" and "draw an animal, a person, and an imaginary animal" tasks in which children were asked to draw an animal, a person, and an imaginary animal after creating any figure with clay. Bodily-kinesthetic intelligence was measured with the "creative movement" task in which children were asked to complete a few physical exercises and follow a clapping rhythm while rowing. Later, children were also required to represent ideas using their body. For instance, the researcher said, "imagine that you are a robot; move like it". For musical intelligence, the researcher conducted a "singing” task. Here, children were simply asked to sing different songs. A musical teacher evaluated musical competency skills, such as sensitivity to pitch, rhythm, and musical ability. Based on results from a confirmatory factorial analysis, the authors observed independence between the BADyG and Gardner's tasks. Moreover, a single $g$ factor did not provide an adequate level of structural adjustment. These results, in terms of intellectual assessment, support MI theory: MI theory does not acknowledge a single $g$ factor based on traditional intelligence theory. Moreover, this study provides evidence that Gardner's tasks might be one way to adequately measure MI.

\section{Theory Can Help Promote Inclusive Education}

MI theory has been adopted in many areas of education including general education classes, special education classes, and education for gifted children (Barton, 2000; Gardner \& Hatch, 1989; Reid \& Romanoff, 1997). Gardner (1999) pointed out that intelligence should be assessed to better understand the teaching and learning process. He recommended that such assessment is conducted in an "intelligence-fair" manner, where is a focus on the capacity to solve problems considering various cultural settings (Gardner \& Hatch, 1989). Moreover, teachers are required to view school education from an individual-centered perspective. However, in practice, current education models have all children learn the same material, in the same way, and at the same pace, and a standard, static, decontextualized instrument assesses progress. Gardner and Boix-Mansilla (1994) suggest that the goals of education should be to understand each child in depth and help optimize development by matching a child's learning level with the appropriate teaching methods. Children have the capacity to utilize all eight intelligences, and most children show different profiles in how they blend these intelligences to solve problems. Thus, uneven profiles on IQ performance subtests shown by children with developmental disorders might be easily explained. Children with dyslexia generally show difficulty in discriminating sounds in language, matching sounds to letter, combining letters to form words, and recalling word images (Patterson, Marshall, \& Coltheart, 1985; Lachmann, Schumacher, \& Van Leeuwen, 2009; Lachmann \& Van Leeuwen, 2007). In contrast, for listening comprehension, children with dyslexia perform as well as typically developing children (Torgesen, 1988). These findings suggest that children with dyslexia have a narrow range of abilities within the verbal-linguistic intelligence domain, whereas they are within a normal range for logical-mathematical intelligence. Moreover, Takahashi and Gyoba (2012) examined the effect of spatial complexity on the capacity of working memory in persons differing along the Autism Spectrum Quotient (AQ: Baron-Cohen, Wheelwright, Skinner, Martin, \& Clubley, 2001). Spatial complexity is thought to an affective variance (Takahashi, Kawachi, \& Gyoba, 2012). Thus, spatial complexity could not be assessed by general intelligence scales such as Wechsler intelligence scales, and it accords for the consideration of the MI theory. As the results, the capacity of working memory for individuals with higher tendency of autism was larger than individuals with lower tendency of autism. In general, individuals with autism showed lower performance of linguistic with materials compared with control group, whereas they performed equivalently to or outperformed with visuo-spatial materials. We can interpret that Takahashi and Gyoba's (2012) results may show the uneven profiles on intelligence subtests among children with developmental disorders. In this view, by examining the effect of MI theory such as an affective variance on perceptual performance, it may be revealed the various characteristics of intelligence in children with developmental disorders. This can provide proper assessment techniques for teacher among children with disabilities, which may enhance inclusive education.

Interestingly, Gardner also thought that MI theory could be applied to the education of gifted children. Moreover, the potent characteristics of this model seem to recognize intellectual abilities related to music and art. From this perspective, there is work that has examined musical and artistic intelligence among children with savant syndrome. Savant syndrome refers to intellectually impaired individuals who display outstanding abilities within very few domains (idiot-savant: Down, 1887). Savant skills can be observed as exceptional memory or exceptional musical or artistic skills (e.g., Heaton \& Wallace, 2004; Howlin, Goode, Hutton, \& Rutter, 2009; Mottron, Dawson, \& Soulieres, 2009; Pring, 2005). Rimland (1978) investigated the proportion of children with savant skills who had parents with an autism spectrum disorder (5400 parents). They showed that 
531 parents $(9.8 \%)$ had savant skills. Among the children of those parents, $53 \%$ had reported outstanding musical skills, $40 \%$ had outstanding memory, $25 \%$ had exceptional mathematical skills, and $19 \%$ had exceptional artistic talent. One thing that savant artists display is a tendency to sketch linear perspective and ignore perceptual size constancy. Without special training, savant artists can use complex graphic strategies, such as linear perspective, foreshortening occlusion, and proportioning (Pring, 2005). Musical savants generally show the ability to recognize, label, and remember pitch information without references. Pitch skill is common among savants who do not even have musical talent (e.g., calendar calculator), suggesting that this skill among musical savants might be based on their outstanding memory ability. Mechanisms involved in these aforementioned savant abilities are not yet fully understood. One hypothesis, the Weak Central Coherence (WCC: Frith, 1989; Happe, 1999) theory, might directly address the underlying mechanisms (Heaton \& Wallace, 2004). The WCC hypothesis assumes that people with an autism spectrum disorder tend to have difficulty processing global information, such as Gestalt or context-dependent information; thus, these people frequently show processing biases in favor of local features. One possible prediction follows from this theory: savant skills are observed on tasks where good featural processing conveys an advantage (Heaton \& Wallace, 2004). As Gardner indicated with MI theory, if musical and artistic abilities are recognized as intelligence, children with savant syndrome can demonstrate exceptional skills in some domains. In contrast, the two-factor model assumes a single $g$ factor; thus, the skills of children with savant syndrome might not be recognized because these children do not score well on measures of general ability. Similar points can be made for children with other developmental disorders. As Happe (1994) showed, IQ scores (e.g., Wechsler scales) for most children with developmental disorders are generally lower than those of typically developing children. Therefore, when assessing intelligence with the two-factor model, these children may be viewed as having low intellectual competency. However, according to the WCC hypothesis, for specific perceptual tasks with processing biases in favor of local features (e.g., visual search or detection tasks), these children show similar or better performance as compared to typically developing children (Dawson, Soulieres, Gernsbacher, \& Mottron, 2007). By assuming various types of intelligence, teachers and researchers can better evaluate the abilities of children with developmental disorders.

Reid and Romanoff (1997) applied MI theory to a gifted education program as part of the Yale Summer Psychology pilot project. In this project, teachers and administrators created curricula in which students must use creative, practical, and analytical thinking to solve actual or virtual real-world problems. One observer for every five children conducted problem-solving assessments. The observer recorded each student's problem solving strategies in detail. For example, the observers administered the tangram puzzles task, which requires spatial and logical-mathematical intelligences. The observer rated each student's performance by using a four-point scale (always evident, strongly evident, evident, or not evident), based on 1) use of a logical strategy without clues; 2) incorporation clues and new information; 3) response time for a complex problem; 4) persistence with difficult tasks; 5) the degree of absorption in the task; and 6) perseverance. Observers employed these criteria such that students who scored within the "always evident" or "strongly evident" category in two out of the three intelligences were identified as having received adequate gifted education services. Reid and Romanoff (1997) reported that students were identified as having gifted performance about $17 \%$ to $20 \%$ within 2 years in math and reading tests compared with students who had no gifted education. These results indicate that education on problem-solving approaches that promote creative, practical, and analytical thinking affects the incensement of school performance in addition to the development of useful problem-solving strategies.

With these curricula, teachers provide students many opportunities to understand important concepts and topics, which induce thinking about a problem in ways different from other students. Moreover, by conducting these programs in regular classrooms for all students, teachers get the opportunity for demonstrative teaching. Actually, Reid and Romanoff (1997) found that such opportunities encouraged classroom teachers to develop curricula and teaching methods to better aid students' understanding. Interestingly, the authors also indicated that these gifted education programs could easily apply to all students. As part of inclusive education, teachers might be required to assess all children's abilities to understand the teaching and learning process. Specifically, teachers need to understand the uneven profiles on intelligence subtests among children with developmental disorders. Some abilities might be higher for these children as compared to typically developing children. This creates a new educational point of view, suggesting that all children, including those with and without disabilities, are smart in some fashion or another (Gottfredson, 2004). However, as is the case at Japanese universities, teachertraining programs do not provide adequate education or proper assessment techniques for working among children with disabilities. Specifically, these programs frequently impose generalized assessment methods or theories based on the traditional two-factor model. For the progress of inclusive education, teacher-training programs must actively provide general education teachers with the necessary skills and assessment techniques that are based on MI theory.

\section{Conclusion}

In this paper, we compared traditional intelligence theory (Spearman's two-factor model) with a more recent intelligence theory (Gardner's multiple intelligence theory) to effectively apply intelligence theory and assessment methods for inclusive education. Considering the various profiles of intelligence shown by children with developmental disorders and intellectual disabilities, we propose the utility of multiple intelligence theory for inclusive education because Gardner's theory recognizes several types of intelligence. These considerations may enhance teacher-training programs in Japanese universities that provide adequate education or proper assessment techniques for working among children with disabilities.

\section{REFERENCES}

Almeida, L. S., Prieto, M. D., Ferreira, A. L., Bermejo, M. R., Ferrando, M., \& Ferrandiz, C. (2010). Intelligence assessment: Gardener multiple intelligence theory as an alternative. Learning and Individual Differences, 20, 225-230. doi:10.1016/j.lindif.2009.12.010

Anderson, M. (1998). Mental retardation, general intelligence and modularity. Learning and Individual Differences, 11, 249-256.

Bar-On, R. (1997). Bar-on emotional quotient inventory (EQ-i): A test 
ofemotional intelligence. Toronto: Multi-Health Systems.

Baron-Cohen, S., Wheelwright, S., Skinner, R., Martin, J., \& Clubley, E. (2001). The autism-spectrum quotient (AQ): Evidence from asperger syndrome/high-functioning autism, males and females, scientists and mathematicians. Journal of Autism and Developmental Disorders, 31, 5-17. doi:10.1023/A:1005653411471

Barton, J. M. (2000). To include or not to include? That is not the question. Journal of Inquiry and Practice, 3, 329-341.

Binet, A., \& Simon, T. (1905). New methods for the diagnosis of the intellectual level of subnormals. In H. H. Goddard (Ed.), Development of intelligence in children (the Binet-Simon Scale). Baltimore: Williams \& Wilkins.

Boake, C. (2002). From the Binet-Simon to the Wechsler-Bellevue: Tracing the history of intelligence testing. Journal of Clinical and Experimental Neuropsychology, 24, 383-405. doi:10.1076/jcen.24.3.383.981

Cattell, J. McK. (1890). Mental tests and measurements. Mind, 15, 373381. doi:10.1093/mind/os-XV.59.373

Dawson, M., Soulières, I., Gernsbacher, M. A., \& Mottron, L. (2007). The level and nature of autistic intelligence. Psychological Science, 18, 657-662. doi:10.1111/j.1467-9280.2007.01954.x

Derksen, J., Kramer, I., \& Katzko, M. (2002). Does a self-report measure for emotional intelligence assess something different than general intelligence? Personality and Individual Differences, 32, 37-48. doi:10.1016/S0191-8869(01)00004-6

Frith, U. (1989). Autism: Explaining the enigma. Cambridge, MA: Blackwell.

Galton, F. (1883). Inquiries into human faculty and its development. London: Macmillan. doi:10.1037/14178-000

Gardner, H., \& Hatch, T. (1998). Multiple intelligences go to school: Educational implications of the theory of multiple intelligences. Educational Researcher, 18, 4-9.

Gardner, H., \& Boix-Mansilla, V. (1994). Teaching for understanding within and acrossthe disciplines. Educational Leadership, 51, 14-18.

Gardner, H. (1983). Frames of mind. New York: Basic Books.

Gardner, H. (1993). Creating minds: An anatomy of creativity seen through the lives of Freud, Einstein, Picasso, Stravinsky, Eliot, Graham, and Gandhi. New York: Basic Books.

Gardner, H. (1998). A multiplicity of intelligences. Scientific American, 9, 19-23.

Gardner, H. (1999). Intelligence reframed: Multiple intelligences for the 21st century. New York: Basic Books.

Gardner, H., Feldman, D., \& Krechevsky, M. (1998). Project spectrum -Building on children's strengths: The experience of project spectrum. New York: Teachers College Press.

Gottfredson, L. S. (2004). Schools and the g factor. The Wilson Quarterly, Summer, 35-45.

Happe, F. G. E. (1994). Wechsler IQ profile and theory of mind in Autism: A research note. Journal of Child Psychology and Psychiatry, 35, 1461-1471. doi:10.1111/j.1469-7610.1994.tb01287.x

Heaton, P., \& Wallace, G. L. (2004). Annotation: The savant syndrome. Journal of Child Psychology and Psychiatry, 45, 899-911. doi:10.1111/j.1469-7610.2004.t01-1-00284.X

Howlin, P., Goode, S., Hutton, J., \& Rutter, M. (2009). Savant skills in autism: Psychometric approaches and parental reports. Philosophical Transactions of the Royal Society of London. Series B, Biological Sciences, 364, 1359-1367. doi:10.1098/rstb.2008.0328

Kaufman, A. S., Long, S. W., \& O’Neal, M. R. (1986). Topical review of the WISC-R for pediatric neuroclinicians. Journal of Child Neurology, 1, 89-98. doi:10.1177/088307388600100202

Koegel, L., Matos-Freden, R., Lang, R., \& Koegel, R. (2012). Interventions for children with autism spectrum disorders in inclusive school settings. Cognitive and Behavioral practice, 19, 401-412. doi:10.1016/j.cbpra.2010.11.003

Lachmann, T., Schumacher, B., \& van Leeuwen, C. (2009). Controlled but independent: Effects of mental rotation and developmental dyslexia in dual task settings. Perception, 38, 1019-1034. doi:10.1068/p6313

Lachmann, T., \& Van Leeuwen, C. (2007). Paradoxical enhancement of letter recognition in developmental dyslexia. Developmental Neuropsychology, 31, 61-77. doi:10.1207/s15326942dn3101_4
Leeper, R. W. (1948). A motivational theory of emotions to replace "emotions as disorganized responses”. Psychological Review, 55, 5-21. doi:10.1037/h0061922

Lincoln, A. J., Courchesne, E., Kilman, B. A., Elmasian, R., \& Allen, M. (1988). A study of intellectual abilities in high functioning people with autism. Journal of Autism and Developmental Disorders, 18, 505-524. doi:10.1007/BF02211870

Mayer, J. D., Salovey, P., \& Caruso, D. (2002). Mayer-salovey-caruso emotional intelligence test (MSCEIT), Version 2.0. Toronto: MultiHealth Systems.

Mottron, L., Dawson, M., \& Soulieres, I. (2009). Enhanced perception in savant syndrome: Patterns, structure and creativity. Philosophical Transactions of the Royal Society of London. Series B, Biological Sciences, 364, 1385-1391. doi:10.1098/rstb.2008.0333

Patterson, K. E., Marshall, J. C., \& Coltheart, M. (1985). Surface dyslexia: Neuropsychological and cognitive studies of phonological reading. Hillsdale, NJ: Lawrence Erlbaum.

Pivik, J., McComas, J., \& Laflamme, M. (2002). Barriers and facilitators to inclusive education. Exceptional Children, 69, 97-107.

Pring, L. (2005). Savant talent. Developmental Medicine \& Child Neurology, 47, 500-503. doi:10.1017/S0012162205000976

Reid, C., \& Romanoff, B. (1997). Using multiple intelligence theory to identify gifted children. Educational Leadership, 55, 71-74.

Robertson, K., Chamberlain, B., \& Kasari, C. (2003). General education teachers' relationships with included students with autism. Journal of Autism and Developmental Disorders, 33, 123-130. doi:10.1023/A:1022979108096

Salovey, P., \& Mayer, J. D. (1990). Emotional intelligence. Imagination, Cognition and Personality, 9, 185-211. doi:10.2190/DUGG-P24E-52WK-6CDG

Schutte, N. S., Malouff, J. M., Hall, L. E., Haggerty, D. J., Cooper, J. T., Golden, C. J. et al. (1998). Development and validation of a measure of emotional intelligence. Personality and Individual Differences, 25, 167-177. doi:10.1016/S0191-8869(98)00001-4

Siegel, D. J., Minshew, N. J., \& Goldstein, G. (1996). Wechsler IQ profiles in diagnosis of high-functioning autism. Journal of Autism and Developmental Disorders, 26, 389-406. doi:10.1007/BF02172825

Spearman, C. (1904). General intelligence, objectively determired and measured. American Journal of Psychology, 15, 201-293. doi:10.2307/1412107

Sternberg, R. J. (1985). Implicit theories of intelligence, creativity, and wisdom. Journal of Personality and Social Psychology, 49, 607-627. doi:10.1037/0022-3514.49.3.607

Sternberg, R. J. (1997). The concept of intelligence and its role in lifelong learning and success. American Psychologist, 52, 1030-1037. doi:10.1037/0003-066X.52.10.1030

Szatmari, P., Tuff, L., Finlayson, M. A., \& Bartolucci, G. (1990). Asperger's syndrome and autism: Neurocognitive aspects. Journal of the American Academy of Child \& Adolescent Psychiatry, 29, 130136. doi:10.1097/00004583-199001000-00021

Takahashi, J., \& Gyoba, J. (2012). Self-rated autistic-like traits and capacity of visual working memory. Psychological Reports, 110, 879-890. doi:10.2466/24.02.04.PR0.110.3.879-890

Takahashi, J. (in Press). Suggestions for teacher training program for inclusive education in Japanese university. Creative Education, 4, 509-513.

Takahashi, J., Kawachi, Y., \& Gyoba, J. (2012). Internal criteria underlying affective responses to visual patterns. Gestalt Theory, 34, 67-80.

Torgesen, J. K. (1988). Studies of children with learning disabilities who perform poorly on memory span tasks. Journal of Learning Disabilities, 21, 605-612. doi:10.1177/002221948802101004

UNESCO (2001). The open file on inclusive education. Paris: UNESCO.

Wechsler, D. (1999). Manual for the wechsler preschool and primary scale of intelligence-revised. San Antonio: Psychological Corporation.

Wechsler, D. (1991). Wechsler intelligence scale for children-Third edition (WISC-III). San Antonio, TX: Psychological Corporation.

Wechsler, D. (1997). WAIS-III administration and scoring manual. New York: The Psychological Corporation.

Yuste, C., Martínez, R., \& Galve, J. L. (1998). BADyG. Technicalmanual. Madrid: CEPE. 